\title{
High Defect Nanoscale ZnO Films with Polar Facets for Enhanced Photocatalytic Performance
}

Premrudee Promdet ${ }^{a}$, Raul Quesada-Cabrera ${ }^{a}$, Sanjayan Sathasivam ${ }^{a}$, Jianwei Li ${ }^{a}$, Arreerat Jiamprasertboon ${ }^{a, b}$, Jian Guo ${ }^{a}$, Alaric Taylor ${ }^{c}$, Claire J. Carmalt ${ }^{a}$ and Ivan P. Parkin ${ }^{a *}$

${ }^{a}$ Materials Chemistry Centre, Department of Chemistry, University College London, 20 Gordon Street, London WC1H 0AJ, UK

Fax: (+44) 20-7679-7463

E-mail: i.p.parkin@ucl.ac.uk

${ }^{b}$ School of Chemistry, Institute of Science, Suranaree University of Technology, 111 University Avenue, Muang, Nakhon Ratchasima, 30000, Thailand

c Department of Electronic \& Electrical Engineering, University College London, Torrington Place, London WC1E 7JE, UK

\section{Abstract}

The fabrication of highly efficient photocatalytic thin films has important consequences for selfcleaning, organic pollutant decomposition and antimicrobial coatings for a wide range of industrial applications. In this work, we developed a simple synthesis method to produce efficient, high surfacearea zinc oxide $(\mathrm{ZnO})$ photocatalytic films using aerosol-assisted chemical vapour deposition. This approach used mixtures of methanol and acetic acid to promote preferential growth and exposure of polar facets, which favour photocatalytic activity. Interestingly, the initial enhanced efficiency of the films was correlated to structural defects, likely oxygen vacancies, as supported by photoluminescence spectroscopy results. Discussion over the influence of such defects on photocatalytic performance is described and the need for strategies to develop high surface-area materials containing stable defects is highlighted.

\section{Introduction}

Oxide semiconductors have attracted interest as an effective material for photocatalyst applications because of their high photocatalytic activity and excellent chemical and mechanical stability ${ }^{1}$. Among the various semiconductors, $\mathrm{ZnO}$, a wide band gap semiconductor (3.37 eV) with a large excitonic binding energy (60 meV) at room temperature, has been considered a promising material in 
photocatalysis, ${ }^{2-5}$ which can be utilized for degradation of organic pollutants ${ }^{6-8}$ and photolysis of water to generate hydrogen. ${ }^{9-11}$ Moreover, ZnO possesses generally hydrophilic surfaces (water contact angle $\theta<90)^{12,13}$ and environmentally friendly features.

Synthesis routes to highly-textured or nanostructured metal-oxide films have attracted attention since these materials often show enhanced functional properties compared to flat conventional thin films. For example, one-dimensional zinc oxide $(\mathrm{ZnO})$ nanostructures, such as nanotubes and nanowires, are attractive for applications in piezoelectric generators, ${ }^{14} \mathrm{UV}$ photodetectors ${ }^{15}$ and solar cells. ${ }^{16}$ Twodimensional hexagonal $\mathrm{ZnO}$ nanoplates have also shown enhanced activities for gas sensing ${ }^{17}$ and photocatalysis applications..$^{4,5,18}$ The photocatalytic properties of semiconductor materials are strongly dependent on their morphology. In the photodegradation of organic compounds, for instance, a greater proportion of exposed polar surfaces has led to enhanced photocatalytic activity. ${ }^{18-20}$ There are three main morphologies related to surfaces in wurtzite $\mathrm{ZnO}$, namely the nonpolar $\{10 \overline{1} 0\}$, semipolar $\{10 \overline{1} 1\}$ and polar $\{0001\}$ facets. The latter intrinsically holds high surface energy and strategies to maximise the $\{0001\}$ surface area are often followed in the synthesis of optimised $\mathrm{ZnO}$ materials, such as inducing preferential growth along the $<001>$ or c-axis. ${ }^{21-26}$ In a photocatalytic reaction, $\mathrm{OH}^{-}$ions preferentially adsorb onto (0001)-Zn surface due to its surface positive charge, favouring formation of $\cdot \mathrm{OH}$ radicals and thus promoting activity. ${ }^{27}$

Among the large number of synthesis methods to produce $\mathrm{ZnO}$ materials, the synthesis of thin films is widely convenient for practical applications. A wide range of deposition techniques can be used to produce $\mathrm{ZnO}$ films, including pulse laser deposition, ${ }^{28}$ molecular beam epitaxy, ${ }^{29}$ thermal evaporation, ${ }^{30}$ chemical vapour deposition ${ }^{31}$ and RF magnetron sputtering,${ }^{32}$ among others. Each one of these techniques has advantages and disadvantages, which include high costs, long reaction times, the use of toxic templates, poor control over physical properties, etc. Aerosol-assisted chemical vapour deposition (AACVD) is a rather simple, scalable and cost-efficient technique that allows good control over physical properties (crystallinity, film thickness, morphology). ${ }^{33-36}$ In AACVD, precursors with low vapour pressure are dissolved in a suitable solvent and the resulting solution is aerosolised and transported into the CVD chamber using a carrier gas. The solvent is not only a vehicle to transport the precursors to the substrate but can also be a key reagent in itself. Thus the solvent of 
choice can play a crucial role to influence the physical properties of the film. ${ }^{35,37,38}$

In the current work, AACVD was used to synthesise highly textured $\mathrm{ZnO}$ films from mixtures of zinc acetate dihydrate, methanol and acetic acid. The presence of acetic acid in the precursor solution had an important influence on the morphology of the films, favouring particle growth along the c-axis. The corresponding photocatalytic activities of the as-deposited films could be explained on the basis of specific surface areas, however their photocatalytic behaviour after annealing was somehow unexpected. Changes in photocatalytic properties were further investigated using photoluminescence spectroscopy $(\mathrm{PL})$. PL studies can provide valuable information on surface defects, electronic structure and charge carrier processes in semiconductor materials. ${ }^{39}$ The presence of surface structural defects, such as oxygen vacancies, can have a huge impact on photocatalytic efficiency since they can promote separation of photogenerated excitons and thus contribute towards charge carrier lifetimes. ${ }^{40,41}$ Furthermore, the injection of photogenerated electrons into oxygen molecules favourably adsorbed in the vicinity of oxygen vacancy sites can promote formation of $\cdot \mathrm{OH}$ radicals, which have a major role on the photocatalytic process. The implementation of similar synthesis routes rendering defected materials with high surface area is key towards industrial applications of thin films.

\section{Experimental section}

\subsection{Thin film synthesis}

All chemicals were used as received from Sigma Aldrich. $\mathrm{ZnO}$ thin films were deposited from zinc acetate dihydrate (98\%) and mixtures of acetic acid (99\%) and methanol (anhydrous, 99.8\%) using aerosol-assisted chemical vapour deposition (AACVD). In this system, a precursor mist was formed using an ultrasonic humidifier (Johnson Matthey) and introduced in the reaction chamber under a controlled flow of nitrogen gas $\left(1.0 \mathrm{~L} \mathrm{~min}^{-1}\right)$. The deposition of $\mathrm{ZnO}$ films was carried out at an optimised temperature of $400^{\circ} \mathrm{C}$ on silica-barrier floating glass substrates (NSG Pilkington Ltd). Each deposition was completed within 50 minutes. All films were well adherent to the substrate, passing the Scotch tape test. ${ }^{42}$

\subsection{Analytical methods}

Film morphology and thickness was studied using top- and side-view scanning electron microscopy 
(SEM) in a JEOL6301 instrument (10 kV). X-ray diffraction (XRD) analysis was carried out using a Bruker-Axs D8 (GADDS) diffractometer. The instrument operated with a monochromated Cu X-ray source with $\mathrm{Cu} \mathrm{K}_{\mathrm{\alpha} 1}(\lambda=1.54056 \AA)$ and $\mathrm{Cu} \mathrm{K}_{\mathrm{a} 2}$ radiation $(\lambda=1.54439 \AA)$ emitted with an intensity ratio of $2: 1$ and a $2 \mathrm{D}$ area X-ray detector with a resolution of $0.01^{\circ}$. Films were analysed with a glancing incident angle $(\theta)$ of $1^{\circ}$. The diffraction patterns obtained were refined using database standards. UV/Vis spectroscopy was performed using a double monochromated Perkin Elmer Lambda 950 UV/Vis/NIR spectrophotometer in the $300-800 \mathrm{~nm}$ range. X-Ray photoelectron spectroscopy (XPS) was performed using a Thermo $\mathrm{K}$ alpha spectrometer with monochromated Al Ka radiation, a dual beam charge compensation system and constant pass energy of $50 \mathrm{eV}$. Survey scans were collected in the range of 0-1200 eV. High-resolution XPS spectra were used for the principal peaks of Zn (2p) and deconvoluted using CasaXPS software with the calibration of $\mathrm{C} 1 \mathrm{~s}$ at $284.5 \mathrm{eV}$. The peaks were modelled using sensitivity factors to calculate the film composition. Room temperature photoluminescence (Renishaw 1000) spectroscopy was employed to study the optical properties of the $\mathrm{ZnO}$ films using a He-Cd laser with a wave-length of $325 \mathrm{~nm}$. The surface roughness of films was characterized by atomic force microscopy (AFM) on a Keysight 5600LS scanning probe microscope taken at a scale of $10 \times 10 \mu \mathrm{m}$.

\subsection{Photocatalytic Test}

The intrinsic photocatalytic properties of the films were investigated during photodegradation of octadecanoic (stearic) acid (95\%), which is used here as a model organic pollutant. ${ }^{43}$ Stearic acid is very stable under UVA irradiation in the absence of a photocatalyst and the photocatalytic degradation (solid-gas reaction) conveniently follows zero-order reaction kinetics above a critical concentration of the acid. In these experiments, the films were dip coated with a thin layer of stearic acid from a 0.05 $\mathrm{M}$ solution in chloroform and then monitored under UVA irradiation over a period of $24 \mathrm{~h}$ using a Perkin Elmer RX-I Fourier transform infrared (FTIR) spectrometer. Plots of integrated areas of characteristic $\mathrm{C}-\mathrm{H}$ infrared bands at 2958, 2923, and $2853 \mathrm{~cm}^{-1}$ were produced and the photodegradation rates were estimated from linear regression of the initial $30-50 \%$ of the curves. A conversion factor from the literature $\left(1 \mathrm{~cm}^{-1} \equiv 9.7 \times 10^{15} \text { molecules of stearic acid }\right)^{44}$ allowed for the estimation of the number of molecules of stearic acid degraded upon irradiation time. The light source used was a UVA $(\lambda=365 \mathrm{~nm})$ Vilber-Lourmat BLB lamp $\left(2 \times 8 \mathrm{~W}, I=1.0 \mathrm{~mW} \mathrm{~cm}^{-2}\right)$. The irradiance of 
the lamp was measured using a UVX radiometer (UVP).

\section{Results and Discussion}

The deposition of $\mathrm{ZnO}$ thin films was carried out using aerosol-assisted chemical vapour deposition AACVD as detailed in the experimental section. Firstly, the vaporised precursor solution (zinc acetate dihydrate, acetic acid and methanol) is transported to tube furnance using nitrogen as carrier gas. On heated substrate, the precursors react followed by the deposition of $\mathrm{ZnO}$. Meanwhile, the waste products are carried away to the exhaust as shown in Scheme 1.

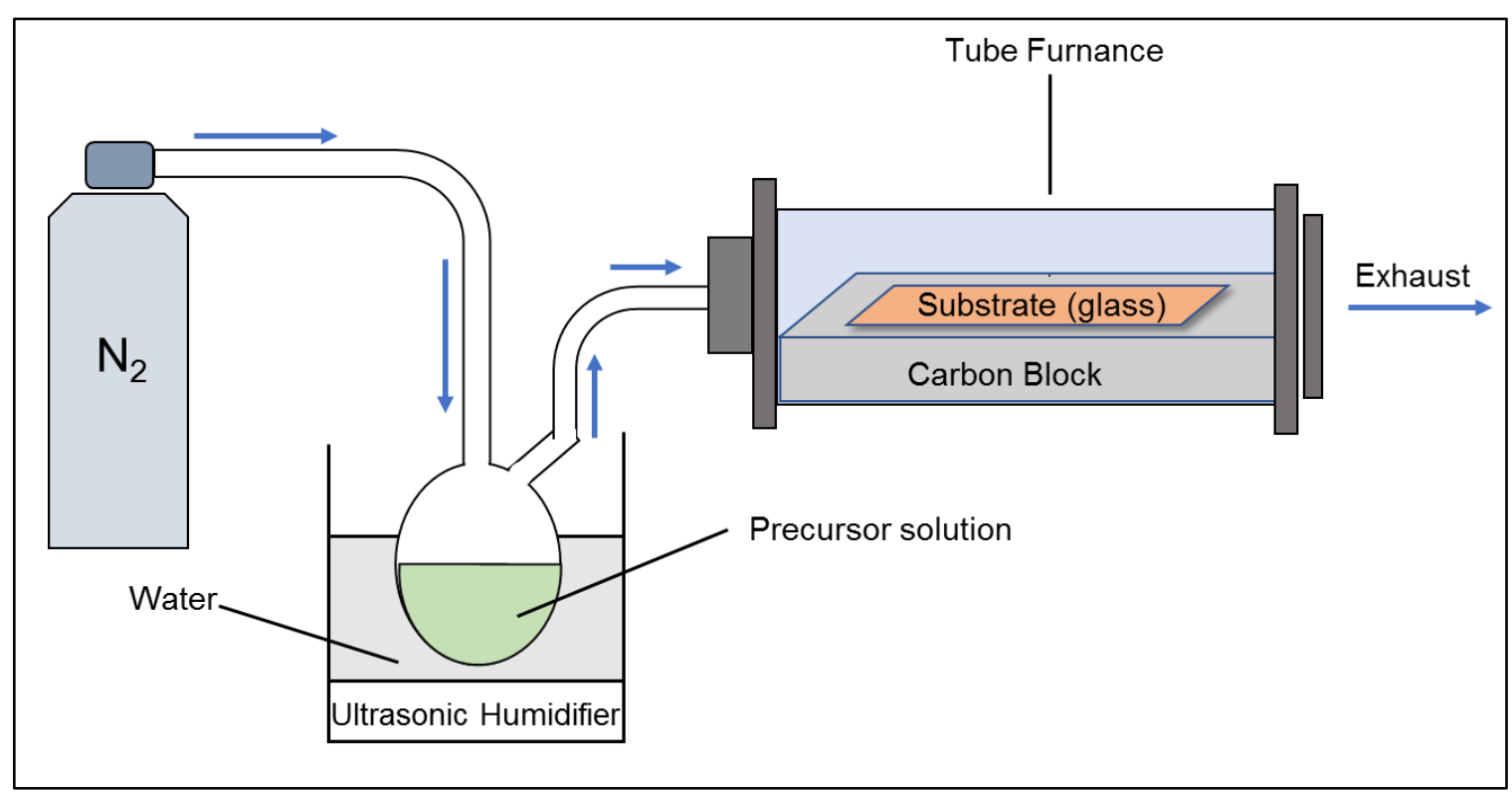

Scheme 1 The illustration of principle of AACVD operation used for $\mathrm{ZnO}$ deposition.

The precursor solutions contained $0.6 \mathrm{~g}$ of zinc acetate dihydrate dissolved in $60 \mathrm{~mL}$ of methanol and additional volumes of acetic acid $(0,1,2$ or $8 \mathrm{~mL}$, corresponding to $0,1.64,3.23$ and 11.76 vol.\%, respectively, henceforth Z-0, Z-1.64, Z-3.23, and Z-11.76). The as-prepared ZnO films showed good adherence and excellent mechanical stability and the additional volumes of acetic acid had a large impact on particle growth and the microstructure of the films (Figure 1). 


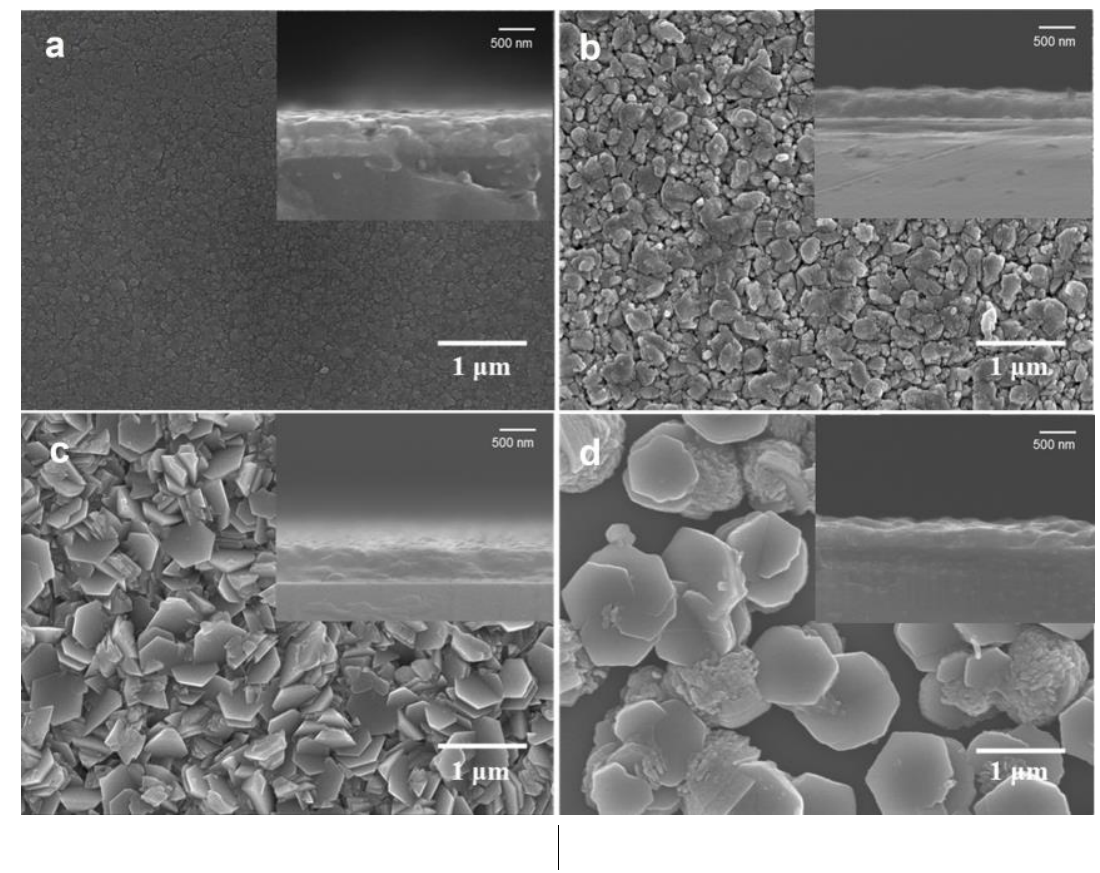

Fig. 1. Scanning electron microscopy (SEM) images showing the impact of different mixtures of methanol and acetic acid on the microstructure of the $\mathrm{ZnO}$ films. The additional volumes of acetic acid were: (a) $0 \mathrm{~mL}$ (0 \%vol); (b) $1 \mathrm{~mL}$ (1.64\%vol); (c) $2 \mathrm{~mL}$ (3.23\%vol); and (d) $8 \mathrm{~mL}$ (11.76\%vol). Inset figures show corresponding side-on views.

The untreated ZnO film showed regular spherical particles with average size of ca. $80 \mathrm{~nm}$. The addition of 1.64 vol.\% of acetic acid into the precursor solution favoured particle growth to an average size of ca. $300 \mathrm{~nm}$. Further additional volumes of acid (3.23 vol.\%) resulted in films exhibiting hexagonal plates of different sizes. Upon addition of 11.76 vol.\% of acetic acid, the films showed large distorted plates. Surface topography of the ZnO films was investigated by AFM, taken at a scale of $10 \times 10 \mu \mathrm{m}^{2}$ as shown in Figure 2. The AFM topography reveals that with increasing acetic acid concentration, the film surface area and surface roughness also increases. The surface area of untreated $\mathrm{ZnO}$ film was $102 \mathrm{\mu m}^{2}$, and treated $\mathrm{ZnO}$ films (1.64, 3.23 and 11.76 vol.\%) possessed 120, 129 and $160 \mu \mathrm{m}^{2}$, respectively. The surface roughness (RMS roughness) of the $11.76 \mathrm{vol}$ \% increased more than five-time compared with the untreated films (Table 1). 

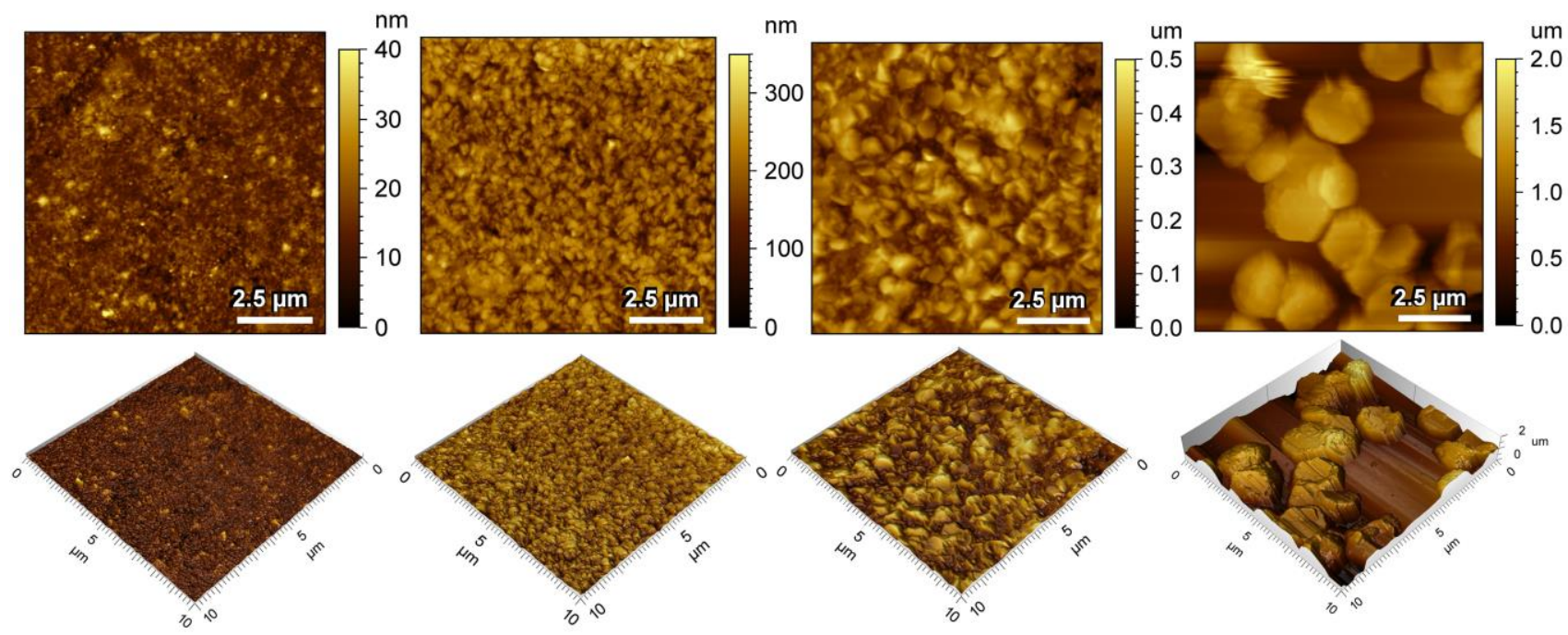

Fig. 2. AFM images of $\mathrm{ZnO}$ thin films coated on glass. (a) $2 \mathrm{D}$ (top) and (b) $3 \mathrm{D}$ (bottom) images of the surface of prepared ZnO films (a) Z-0; (b) Z-1.64; (c) Z-3.23 and (d) Z-11.76 respectively, at a scale of $10 \times 10 \mu \mathrm{m}$.

These film morphologies correlated to previous observations ${ }^{45,46}$ and are determined by the grain growth process that occurs after the nucleation step during CVD. In the absence of acetic acid, the growth rate along the $c$-axis is similar to that of the radial axis (growing equivalent planes), thus resulting in small round particles. ${ }^{47,48}$ However, upon addition of acetic acid, the selective adsorption of acetate anions on the $\{0001\}$ facets inhibited crystal growth along the $c$-axis and promoted growth along the a-axis, with formation of hexagonal plates. ${ }^{46,49}$ Furthermore, side-on SEM analysis (Figure 1, inset) showed film thicknesses decreasing from ca. $700 \mathrm{~nm}(0$ vol.\%) to $290 \mathrm{~nm}(11.76$ vol.\%) (Table 1).

Table 1. Structural, optical and functional parameters of $\mathrm{ZnO}$ films from different mixtures of methanol and acetic acid in the precursor mixture.

\begin{tabular}{|c|c|c|c|c|c|c|c|c|}
\hline \multirow[t]{2}{*}{ Sample } & \multicolumn{2}{|c|}{ Acetic acid } & \multirow{2}{*}{$\begin{array}{c}\text { Film } \\
\text { thickness } \\
(\mathrm{nm})\end{array}$} & \multirow[t]{2}{*}{$\begin{array}{l}E_{b g} \\
(e V)\end{array}$} & \multirow[t]{2}{*}{$\begin{array}{c}\text { Surface } \\
\text { area }\left(\mu \mathrm{m}^{2}\right)\end{array}$} & \multirow{2}{*}{$\begin{array}{c}\text { RMS } \\
\text { roughness } \\
(\mathrm{nm})\end{array}$} & \multicolumn{2}{|c|}{$\begin{array}{c}\xi \\
\left(\text { molec photon }^{-1}\right) \\
\end{array}$} \\
\hline & $(m L)$ & (\%vol) & & & & & As-dep & Anneal \\
\hline Z-0 & 0 & 0 & 700 & 3.3 & 102 & 60 & 1.1 & 1.2 \\
\hline Z-1.64 & 1 & 1.64 & 470 & 3.3 & 120 & 67 & 3.1 & 0.8 \\
\hline Z-3.23 & 2 & 3.23 & 480 & 3.3 & 129 & 135 & 6.9 & 1.0 \\
\hline Z-11.76 & 8 & 11.76 & 290 & 3.3 & 160 & 354 & 4.2 & 1.2 \\
\hline
\end{tabular}


This effect was attributed to a decrease in zinc hydroxide molecules $\left(\mathrm{Zn}(\mathrm{OH})_{2}\right)$ upon increasing volumes of acetic acid in the precursor solutions. This phenomenon might result from the excess $\mathrm{CH}_{3} \mathrm{COO}^{-}$anions and $\mathrm{H}^{+}$(eqn (3)) upon the addition of acetic-acid to the precursor solutions, reducing free methanol in the precursors by promoting eqn (4) to proceed to right side and decrease the ester elimination reaction, which might reduce $\mathrm{Zn}(\mathrm{OH})_{2}$. The ester elimination reaction could occur between zinc acetate and methanol to form $\mathrm{Zn}(\mathrm{OH})_{2}$ and methyl acetate ${ }^{50}$. Dehydration of $\mathrm{Zn}(\mathrm{OH})_{2}$ is important in formation of crystalline $\mathrm{ZnO}$ and would generate nuclei as the aerosol droplets are transported to the heated substrate.

$$
\begin{array}{rlc}
\mathrm{Zn}\left(\mathrm{CH}_{3} \mathrm{COO}\right)_{2} & \stackrel{2 \mathrm{CH}_{3} \mathrm{OH}}{\longrightarrow} & \mathrm{Zn}(\mathrm{OH})_{2}+2 \mathrm{CH}_{3} \mathrm{COOCH}_{3} \\
\mathrm{Zn}(\mathrm{OH})_{2} & \stackrel{\text { heating }}{\longrightarrow} & \mathrm{ZnO}+\mathrm{H}_{2} \mathrm{O} \uparrow \\
\mathrm{CH}_{3} \mathrm{COOH} & \stackrel{\text { equilibrium }}{\longrightarrow} & \mathrm{H}^{+}+\mathrm{CH}_{3} \mathrm{COO} \\
\mathrm{CH}_{3} \mathrm{OH}+\mathrm{H}^{+} & \stackrel{\text { equilibrium }}{\longleftrightarrow} \mathrm{CH}_{3} \mathrm{OH}_{2}^{+}
\end{array}
$$

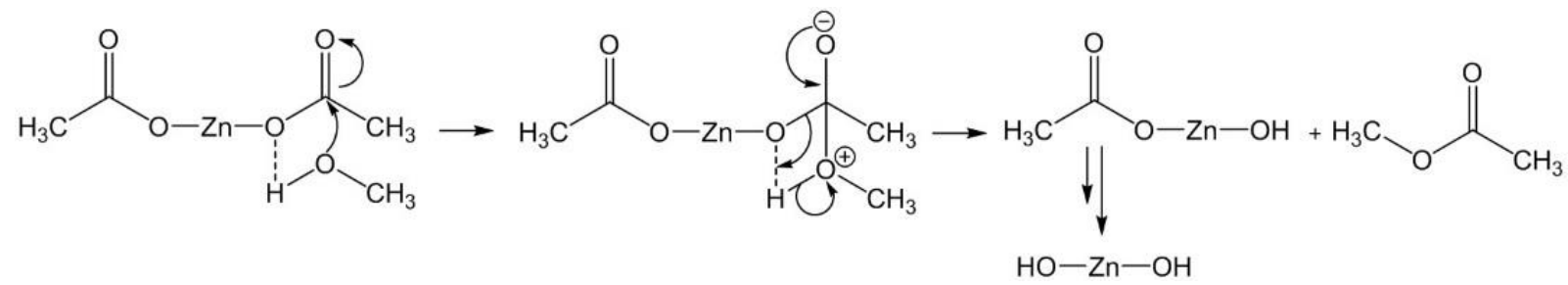

Scheme 2. Alcoholysis ester elimination reaction between zinc acetate and methanol to form $\mathrm{Zn}(\mathrm{OH})_{2}$ and methyl acetate ${ }^{50}$

Less $\mathrm{Zn}(\mathrm{OH})_{2}$ can reduce the $\mathrm{ZnO}$ nucleation rate and the number of nucleation sites. Thus, the crystals in acid-treated $\mathrm{ZnO}$ samples could obtain more lateral space to grow up and their grains get increasingly bigger.

Examination of the $\mathrm{Zn} 2 \mathrm{p}$ core level XPS spectra of all $\mathrm{ZnO}$ films showed the $\mathrm{Zn} 2 \mathrm{p}_{3 / 2}$ peak at 1021.7 $\mathrm{eV}$ corresponding to $\mathrm{Zn}$ in the $2+$ oxidation state. ${ }^{51}$. X-ray diffraction analysis confirmed the presence of hexagonal wurtzite $\mathrm{ZnO}$ phase (P63mc space group, $a=3.2490 \AA, b=3.2490 \AA$, and $c=5.2050$ $\AA$; ICCD Card No. 5-0664) and the preferential growth in the films with relatively high concentration of acetic acid in the precursor solution (Figure 3a).

The preferential growth of a particular plane can be represented by the texture coefficient (TC), 
expressed as: $: 52,53$

$$
T C=\frac{I(h k l) / I_{0}(h k l)}{n-1 \sum_{i=1}^{i=n} I(h k l) / I_{0}(h k l)}
$$

where, the condition for preferential growth is observed in diffraction peaks with $\mathrm{TC}>1$. In this equation, $I(h k l)$ and $I_{0}(h k l)$ are peak intensities of a sample and reference (JCPDS data card 01-1136), respectively, and $n$ is the number of diffraction peaks considered. The TC values calculated for different orientations in the $\mathrm{ZnO}$ films are shown in Figure $\mathbf{3 b}$.

(a)

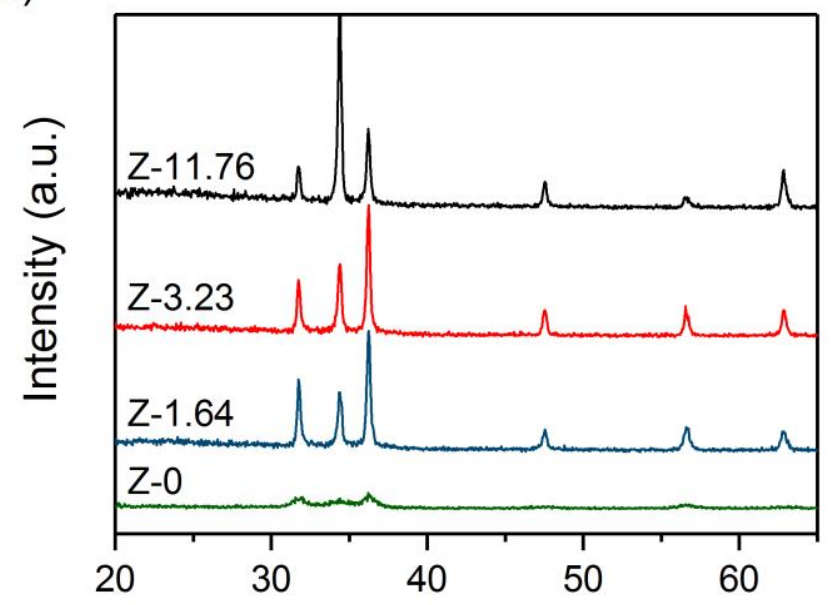

(b)

$2 \theta\left({ }^{\circ}\right)$

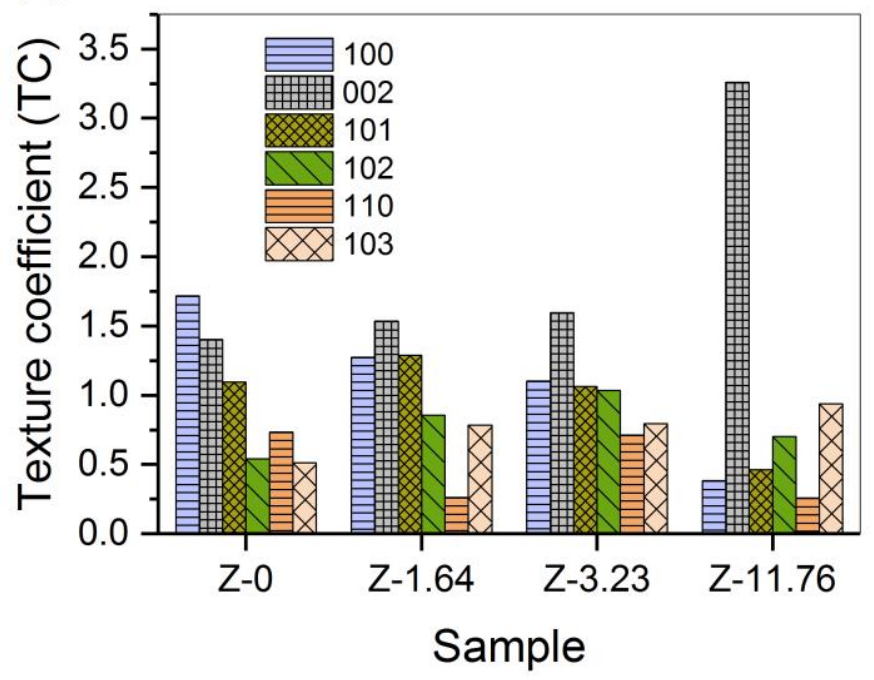

Fig. 3. (a) X-ray diffraction analysis and (b) corresponding texture coefficients of ZnO films prepared with different mixtures of methanol and acetic acid. The additional volumes of acetic acid into the precursor mixtures were (a) $0 \mathrm{~mL}$ (0\%vol), Z-0; (b) $1 \mathrm{~mL}$ (1.64\%vol), Z-1.64; (c) $2 \mathrm{~mL}$ (3.23\%vol), Z-3.23; and (d) $8 \mathrm{~mL}(11.76 \% \mathrm{vol}), \mathrm{Z}-11.76$.

The untreated sample exhibited broad, weak diffraction peaks, as may be expected from diffraction 
of nanoparticles (80 $\mathrm{nm})$, although it can also be due to relatively poor crystallinity. In the absence or at relatively low concentrations (1.64 vol.\%) of acetic acid in the precursor mixtures, the resulting films showed TC values above 1 for several peaks, indicating relatively random orientation of the particles, as observed in the SEM images (Figure 1). Higher concentrations of acetic acid, however, encouraged preferential growth in the (002) plane, with the highest TC value of 3.26 for the 11.76 vol.\% sample.

With respect to optical properties, all films showed high transparency to the visible range (Figure 4). Diffuse transmission spectra changed from $<10 \%(0$ vol. $\%)$ to $>70 \%(11.76$ vol. $\%)$, which resulted in increasing haze factors and a strong light trapping ability upon addition of acetic acid in the precursor mixture (Table 1) as well as enhancing light absorption as shown is $\mathbf{S 1 .}$

(a)

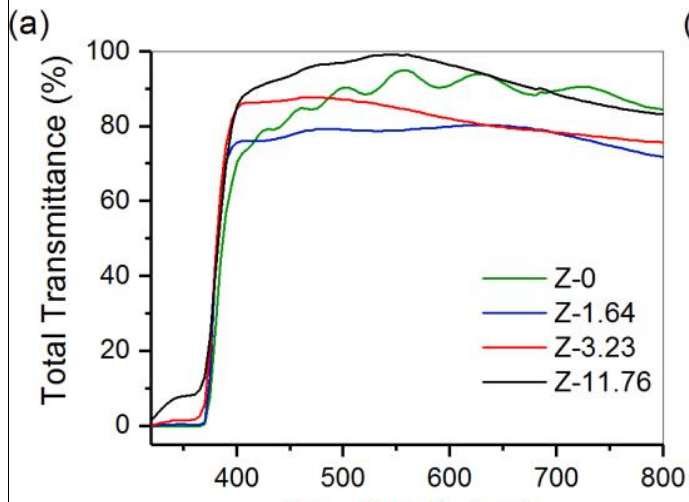

(c)

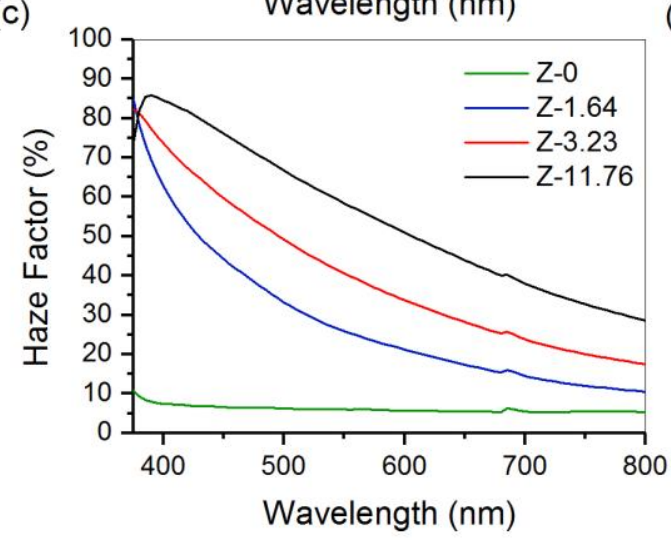

(b)

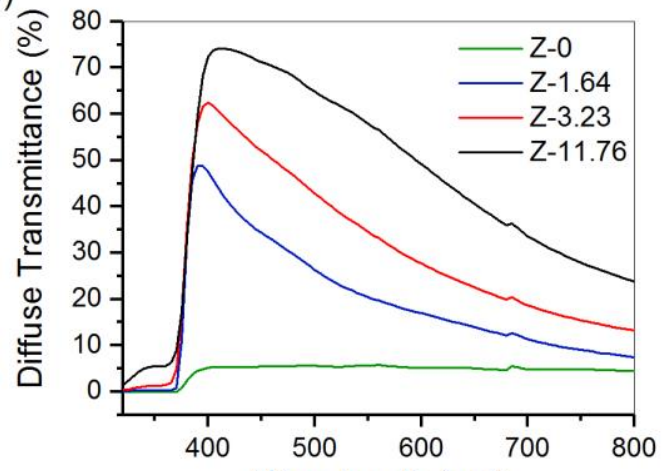

(d)

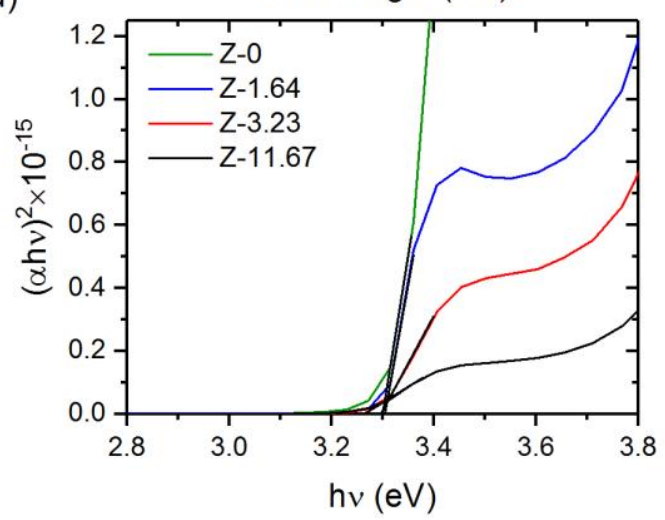

Fig. 4 (a) Total and (b) diffuse transmittance of the ZnO films as deposited from different mixtures of methanol and acetic acid. (c) Haze factor and (d) Tauc plots allowing an estimation of band gap energies of $\mathrm{ZnO}$ films prepared with different mixtures of methanol and acetic acid. The additional volumes of acetic acid into the precursor mixtures were (a) $0 \mathrm{~mL}(0 \%$ vol), Z-0; (b) $1 \mathrm{~mL}$ (1.64 \%vol), Z-1.64; (c) $2 \mathrm{~mL}$ (3.23 \%vol), Z-3.23; and (d) $8 \mathrm{~mL}$ (11.76 \%vol), Z-11.76. 
The onset of absorption edges was observed at approximately $\lambda=370 \mathrm{~nm}$ (Figure 4), as it corresponds to the characteristic band gap absorption of $\mathrm{ZnO}$. Band gap energy $\left(E_{b g}\right)$ values ranged from 3.29 to $3.33 \mathrm{eV}$ (Table 1), as estimated from the Tauc model in the high absorption region assuming a direct transition between valence and conduction bands. ${ }^{54}$

The photocatalytic properties of the as-deposited $\mathrm{ZnO}$ films were evaluated during degradation of stearic acid under UVA irradiation $\left(\lambda=365 \mathrm{~nm}, I=1.0 \mathrm{~mW} \mathrm{~cm}^{-1}\right)$. The corresponding degradation curves are plotted against irradiation time in Figure 5a. The trend of degradation curves was as expected with high surface-area samples (3.23 and 11.76 vol.\%) being the most effective photocatalysts. In the case of Z-3.23, full mineralisation was reached within $24 \mathrm{~h}$ of irradiation. The fitting of the initial degradation steps (zero order kinetics) allowed for the estimation of formal quantum efficiencies ( $\xi$, units molec photon ${ }^{-1}$ ), given as number of acid molecules degraded per incident photon (Figure 5b).

(a)

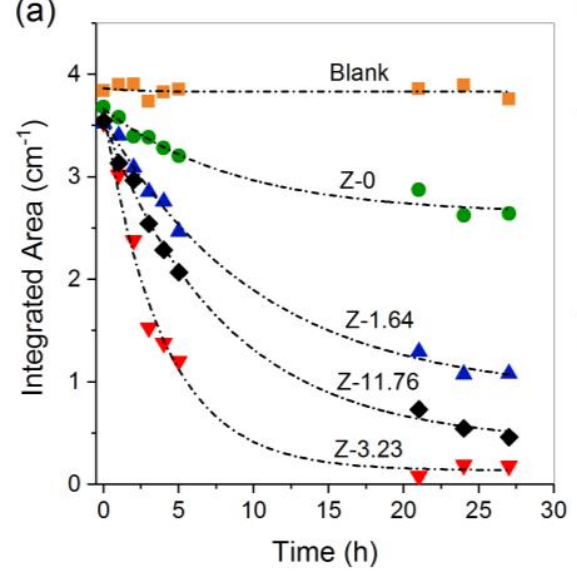

(b)

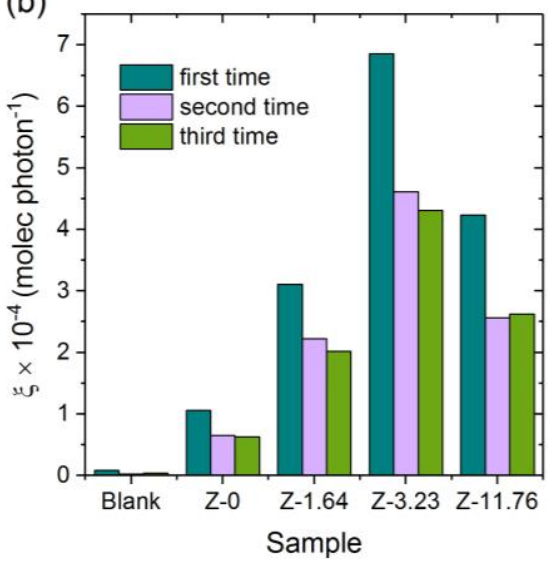

(c)

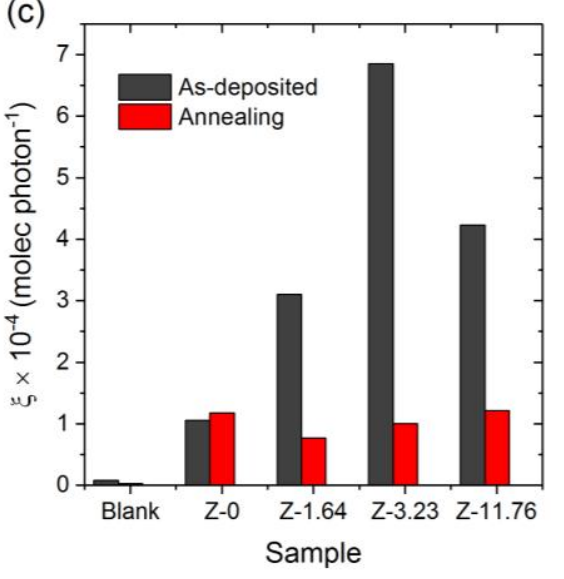

Fig. 5. (a) Integrated areas of the IR spectra of stearic acid upon irradiation time (UVA, $\lambda=365 \mathrm{~nm}$, $\left.I=1.0 \mathrm{~mW} \cdot \mathrm{cm}^{-2}\right)$; (b) corresponding formal quantum efficiencies $(\xi)$, given as molecules degraded per incident photon (units, molec photon ${ }^{-1}$ ), upon cycle experiments; and (c) $\xi$ values before and after annealing to $500 \mathrm{C}$ during $6 \mathrm{~h}$ in air. A blank reference corresponds to the glass substrate without the photocatalytic coating.

The influence of any particular crystallographic plane exposed to the media could not be established unambiguously in these experiments, however Vallejos et al. ${ }^{51}$ attributed the efficient photocatalytic performance of the hexagonal plates as due to exposed $\{001\}$ facets. It is worth noting that cycle 
experiments resulted in a significant drop of the initial $\xi$ values of the as-deposited films. A consistent drop of activity during cycle experiments is typically attributed to surface poisoning due to carbon contamination during the photodegradation of organic pollutants. During our studies, however, the $\mathrm{ZnO}$ films remained active, showing constant $\xi$ values, within error margins, after the first run (Figure 5b). This observation suggests that the initial enhanced values could be related to structural features or extrinsic properties, such as oxygen vacancies that may be depleted during reaction, although partial surface deactivation of the films cannot be ruled out. Further unusual behaviour was observed upon annealing of the as-deposited films to $500{ }^{\circ} \mathrm{C}$ for $6 \mathrm{~h}$ in air. This annealing treatment is often carried out to either enhance crystallinity or clean surfaces of potential carbon contamination and it is usually reflected in a slight improvement in photocatalytic efficiency. Surprisingly, only the untreated sample showed an improved activity after annealing (Figure 5c) while the $\xi$ values of the acid-treated samples dropped significantly. It is important to note that the physical properties of the samples did not change noticeably after annealing, as evidenced by XRD and SEM analysis (S2 and S3).

Insight into the photocatalytic behaviour of the $\mathrm{ZnO}$ films was sought upon exploration of structural defects using photoluminescence $(\mathrm{PL})$ spectroscopy. The PL spectra of $\mathrm{ZnO}$ films commonly exhibits two main features, a near-band-edge (NBE) emission band around $375 \mathrm{~nm}$ and a deep-level emission (DLE) broad band in the visible range (Figure 6). ${ }^{39,55}$ 
(a)

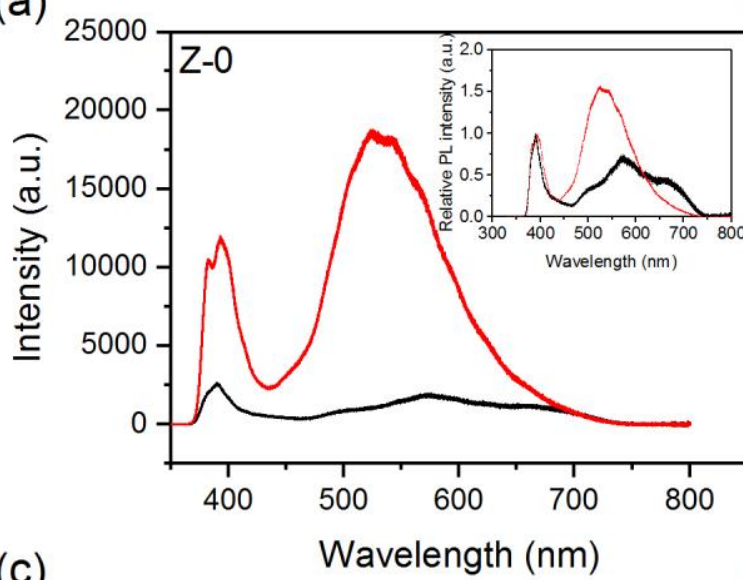

(c)

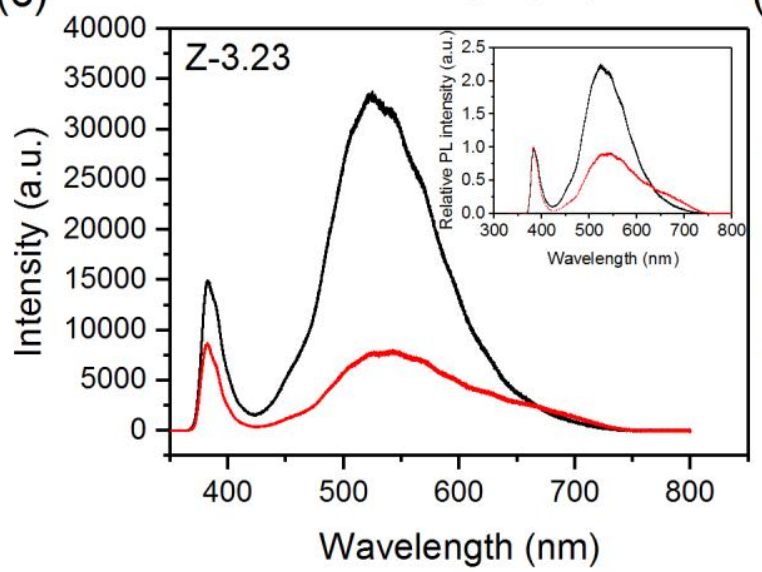

(b)

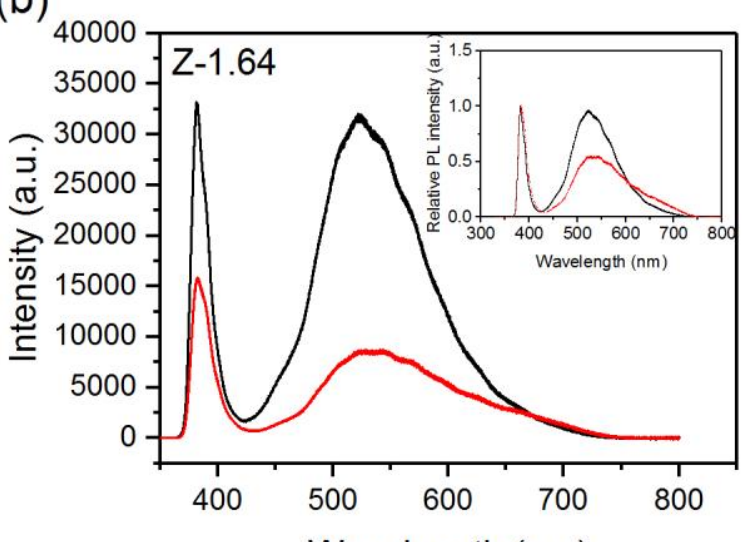

(d)

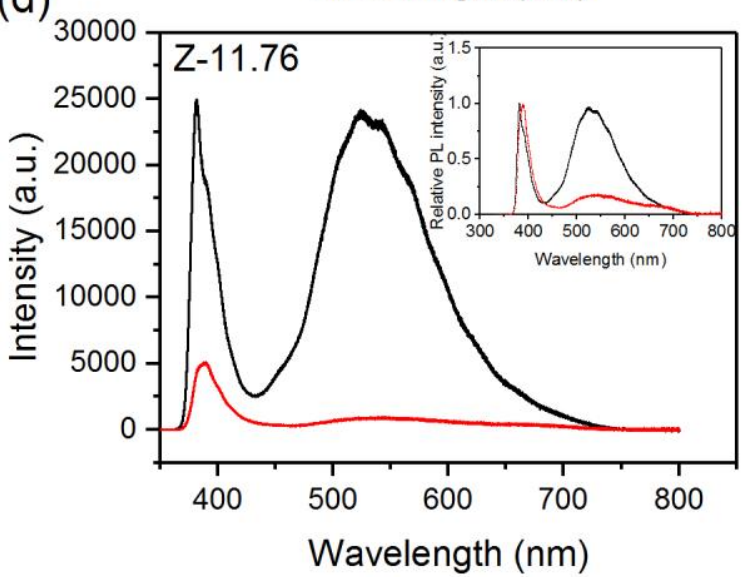

Fig. 6. Photoluminescence spectra of as-prepared (black line) and annealed (red line) $\mathrm{ZnO}$ films at the additional volumes of acetic acid being: (a) $0 \mathrm{~mL}$ (0\%vol); (b) $1 \mathrm{~mL}$ (1.64\%vol); (c) $2 \mathrm{~mL}$ $(3.23 \% \mathrm{vol})$; and (d) $8 \mathrm{~mL}(11.76 \% \mathrm{vol})$ recorded under an excitation wavelength of $325 \mathrm{~nm}$. Inset figures are normalised with respect to the maximum intensity of the NBE band at $380 \mathrm{~nm}$.

The UV emission band is due to the recombination of photogenerated electrons from the conduction band to the valence band. In general, the strong PL means high recombination of photogenerated carriers, suggesting the low photocatalytic activity. The position of free recombination of excitons at $375 \mathrm{~nm}(3.31 \mathrm{eV})$ was in good agreement with the $E_{b g}$ values estimated for our films (Table 1). The deep-level emission (DLE) broad band centered at $550 \mathrm{~nm}(2.3 \mathrm{eV})$ has been associated to single ionized oxygen vacancies, oxygen antisites, zinc vacancies, and oxygen deficiency ${ }^{56-59}$ The concentration of oxygen vacancies can be estimated by the ratio of visible emission and UV emission intensity (IVvis/luv). $)^{4,5,60}$ 
Oxygen vacancies can bind photo-induced electrons enhancing the separation of photogenerated excitons, thus promoting photocatalytic efficiency. ${ }^{61,62}$ Therefore, as a general rule, high $I_{V i s} / l_{u v}$ ratio (i.e. high concentration of defects) may be indicative of enhanced photocatalytic efficiency. Figure 6 shows PL spectra (excitation wavelength of $325 \mathrm{~nm}$ ) before and after the annealing of $\mathrm{ZnO}$ films at $500{ }^{\circ} \mathrm{C}$ in air. Close inspection of the figure revealed a relative drop in intensity of the DLE band $\left(I_{v i s}\right)$ relative to the NBE band $\left(I_{u v}\right)$ after annealing of the acid-treated samples, with the untreated sample (Z-0) showing the opposite trend. This is highlighted in the inset plots in Figure 6, which show the normalised PL spectra with reference to the maximum intensity of the corresponding NBE bands.

The change in the normalised $I_{v i s}$, i.e. $\Delta I_{\text {vis }}=I_{\text {vis }}$ (annealed) $-I_{\text {vis }}$ (as-deposited), is plotted in Figure 7 against the corresponding change in $\xi$ values as estimated before and after annealing of the samples.

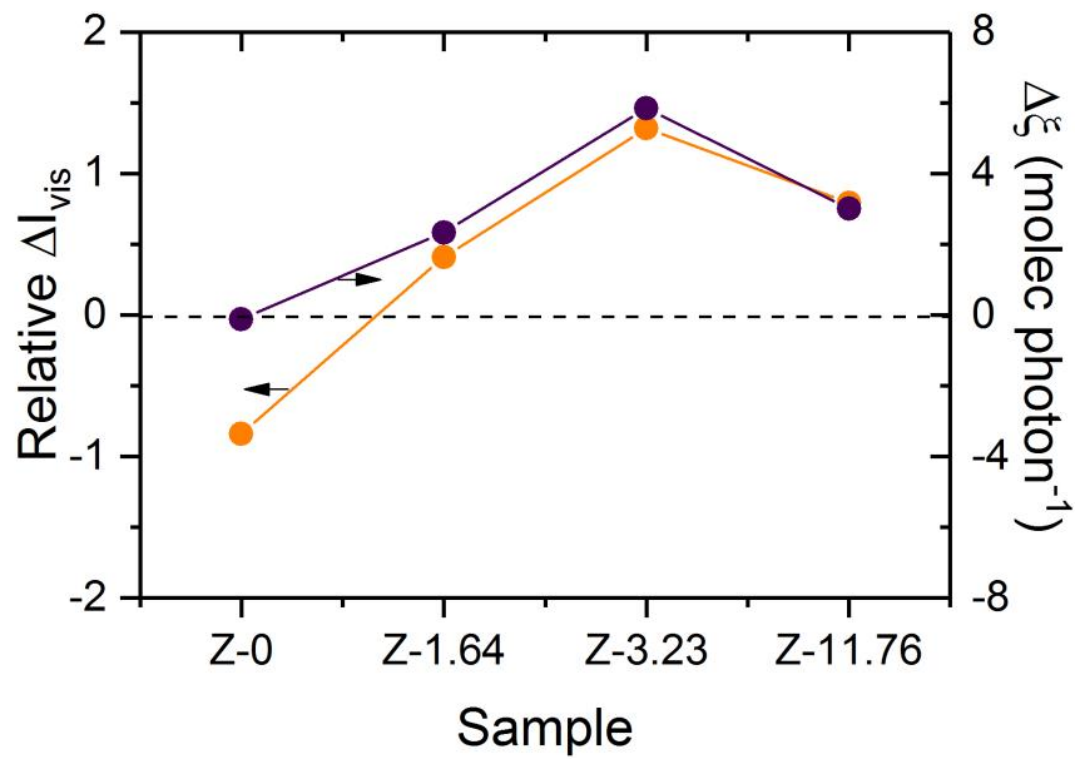

Fig. 7. Trends of relative band intensity change, i.e. $\Delta I_{v i s}=I_{\text {vis }}$ (annealed) - $I_{\text {vis }}$ (as-deposited) with respect to their corresponding NBE band maxima (luv) and change in $\xi$ before and after annealing.

The close correlation between these trends, particularly in the case of the acid-treated samples (Z$1.64, \mathrm{Z}-3.23$ and Z-11.76), suggests that the initial enhanced photocatalytic efficiency of these $\mathrm{ZnO}$ films is indeed related to oxygen vacancies that are either depleted during the photocatalytic process or can heal upon exposure to air at high temperature.

\section{Conclusion}


Highly textured, defected $\mathrm{ZnO}$ thin films were deposited from aerosol assisted chemical vapour deposition on glass substrates. The addition of small volumes of acetic acid in the precursor solution had a huge impact on particle growth and film morphology, promoting lateral grain growth and exposing polar facets for an optimum photocatalytic performance. The initial formal efficiencies of the as-deposited films were found to decrease suddenly, either upon photodegradation of the organic pollutant or under annealing in air. This drop in activity was consistent with changes in photoluminescence spectroscopy and correlated with the depletion or healing of defects, likely oxygen vacancies. This encouraging result is a step forward towards the fabrication of optimised photocatalytic materials and it calls for the implementation of synthesis strategies of high surface-area photocatalysts with stable defects.

\section{Acknowledgements}

This work is supported by The Development and Promotion of Science and Technology Talents Project for a fellowship of P. Promdet. IPP and CJC thank EPSRC for grant EP/L0177709/1.

\section{References}

(1) Hoffmann, M. R.; Martin, S. T.; Choi, W.; Bahnemann, D. W. Environmental Applications of Semiconductor Photocatalysis. Chem. Rev. 1995, 95 (1), 69-96. https://doi.org/10.1021/cr00033a004.

(2) Yassitepe, E.; Yatmaz, H. C.; Öztürk, C.; Öztürk, K.; Duran, C. Photocatalytic Efficiency of ZnO Plates in Degradation of Azo Dye Solutions. J. Photochem. Photobiol. A Chem. 2008, 198 (1), 1-6. https://doi.org/10.1016/j.jphotochem.2008.02.007.

(3) Xie, W.; Li, Y.; Sun, W.; Huang, J.; Xie, H.; Zhao, X. Surface Modification of ZnO with Ag Improves Its Photocatalytic Efficiency and Photostability. J. Photochem. Photobiol. A Chem. 2010, 216 (2-3), 149-155. https://doi.org/10.1016/j.jphotochem.2010.06.032.

(4) Wang, J.; Yang, J.; Li, X.; Feng, B.; Wei, B.; Wang, D.; Zhai, H.; Song, H. Effect of Surfactant on the Morphology of $\mathrm{ZnO}$ Nanopowders and Their Application for Photodegradation of Rhodamine B. Powder Technol. 2015, $286 \quad$ (3), 269-275. https://doi.org/10.1016/j.powtec.2015.08.030.

(5) Zhang, X.; Qin, J.; Xue, Y.; Yu, P.; Zhang, B.; Wang, L.; Liu, R. Effect of Aspect Ratio and Surface Defects on the Photocatalytic Activity of ZnO Nanorods. Sci. Rep. 2014, 4, 4-11. https://doi.org/10.1038/srep04596.

(6) Venkatesha, T. G.; Arthoba Nayaka, Y.; Viswanatha, R.; Vidyasagar, C. C.; Chethana, B. K. Electrochemical Synthesis and Photocatalytic Behavior of Flower Shaped ZnO Microstructures. 
Powder Technol. 2012, 225, 232-238. https://doi.org/10.1016/j.powtec.2012.04.021.

(7) Hong, R. Y.; Li, J. H.; Chen, L. L.; Liu, D. Q.; Li, H. Z.; Zheng, Y.; Ding, J. Synthesis, Surface Modification and Photocatalytic Property of ZnO Nanoparticles. Powder Technol. 2009, 189 (3), 426-432. https://doi.org/10.1016/j.powtec.2008.07.004.

(8) Xie, J.; Li, Y.; Zhao, W.; Bian, L.; Wei, Y. Simple Fabrication and Photocatalytic Activity of ZnO Particles with Different Morphologies. Powder Technol. 2011, 207 (1-3), 140-144. https://doi.org/10.1016/j.powtec.2010.10.019.

(9) Maeda, K.; Takata, T.; Hara, M.; Saito, N.; Inoue, Y.; Kobayashi, H.; Domen, K. GaN : ZnO Solid Solution as a Photocatalyst for Visible-Light-Driven Overall Water Splitting. 2005, 8286-8287. https://doi.org/10.1021/ja0518777.

(10) Yang, X.; Wolcott, A.; Wang, G.; Sobo, A.; Fitzmorris, R. C.; Qian, F.; Zhang, J. Z.; Li, Y. Nitrogen-Doped ZnO Nanowire Arrays for Photoelectrochemical Water Splitting 2009. 2009, 2 7.

(11) Wang, M.; Ren, F.; Zhou, J.; Cai, G.; Cai, L.; Hu, Y. N Doping to ZnO Nanorods for Photoelectrochemical Water Splitting under Visible Light : Engineered Impurity Distribution and Terraced Band Structure. Nat. Publ. Gr. 2015, No. July, 1-13. https://doi.org/10.1038/srep12925.

(12) Huang, L.; Lau, S. P.; Yang, H. Y.; Leong, E. S. P.; Yu, S. F.; Prawer, S. Stable Superhydrophobic Surface via Carbon Nanotubes Coated with a ZnO Thin Film. J. Phys. Chem. B 2005, 109 (16), 7746-7748. https://doi.org/10.1021/jp046549s.

(13) Sun, R.-D.; Nakajima, A.; Fujishima, A.; Watanabe, T.; Hashimoto, K. Photoinduced Surface Wettability Conversion of $\mathrm{ZnO}$ and $\mathrm{TiO}_{2}$ Thin Films. J. Phys. Chem. B 2001, 105 (10), 1984 1990. https://doi.org/10.1021/jp002525j.

(14) Shoaee, S.; Briscoe, J.; Durrant, J. R.; Dunn, S. Acoustic Enhancement of polymer/ZnO Nanorod Photovoltaic Device Performance. Adv. Mater. 2014, 26 (2), 263-268. https://doi.org/10.1002/adma.201303304.

(15) Leung, Y. H.; He, Z. B.; Luo, L. B.; Tsang, C. H. A.; Wong, N. B.; Zhang, W. J.; Lee, S. T. ZnO Nanowires Array P-N Homojunction and Its Application as a Visible-Blind Ultraviolet Photodetector. Appl. Phys. Lett. 2010, 96 (5), 3-6. https://doi.org/10.1063/1.3299269.

(16) Han, J.; Fan, F.; Xu, C.; Lin, S.; Wei, M.; Duan, X.; Wang, Z. L. ZnO Nanotube-Based DyeSensitized Solar Cell and Its Application in Self-Powered Devices. Nanotechnology 2010, 21 (40). https://doi.org/10.1088/0957-4484/21/40/405203.

(17) Liu, J.; Chen, X.; Wang, W.; Liu, Y.; Huang, Q.; Guo, Z. Self-Assembly of [1010] Grown ZnO Nanowhiskers with Exposed Reactive (0001) Facets on Hollow Spheres and Their Enhanced Gas Sensitivity. CrystEngComm 2011, 13 (10), 3425. https://doi.org/10.1039/c0ce00821d.

(18) Guoquiang Li, and S. C. T. A. M. T. V.-S. Shape and Size Effects of ZnO Nanocrystals on Photocatalytic Activity. J. Am. Chem. Soc. 2009, 131 (1), 12540-12541.

(19) Jang, E. S.; Won, J. H.; Hwang, S. J.; Choy, J. H. Fine Tuning of the Face Orientation of ZnO Crystals to Optimize Their Photocatalytic Activity. Adv. Mater. 2006, 18 (24), 3309-3312. https://doi.org/10.1002/adma.200601455.

(20) Ali, T. T.; Narasimharao, K.; Parkin, I. P.; Carmalt, C. J.; Sathasivam, S.; Basahel, S. N.; Bawaked, S. M.; Al-Thabaiti, S. A. Effect of Pretreatment Temperature on the Photocatalytic Activity of Microwave Irradiated Porous Nanocrystalline ZnO. New J. Chem. 2015, 39 (1), 321 332. 
(21) Ikizler, B.; Peker, S. M. Effect of the Seed Layer Thickness on the Stability of ZnO Nanorod Arrays. Thin Solid Films 2014, 558, 149-159. https://doi.org/10.1016/j.tsf.2014.03.019.

(22) Ikizler, B.; Peker, S. M. Synthesis of TiO2coated ZnO Nanorod Arrays and Their Stability in Photocatalytic Flow Reactors. Thin Solid Films 2016, 605, 232-242. https://doi.org/10.1016/j.tsf.2015.11.083.

(23) Feng, W.; Chen, J.; Hou, C. Growth and Characterization of ZnO Needles. Appl. Nanosci. 2014, 4 (1), 15-18. https://doi.org/10.1007/s13204-012-0174-9.

(24) Yang, J. L.; An, S. J.; Park, W. I.; Yi, G.-C.; Choi, W. Photocatalysis Using ZnO Thin Films and Nanoneedles Grown by Metal-Organic Chemical Vapor Deposition. Adv. Mater. 2004, 16 (18), 1661-1664. https://doi.org/10.1002/adma.200306673.

(25) Mihailova, I.; Gerbreders, V.; Tamanis, E.; Sledevskis, E.; Viter, R.; Sarajevs, P. Synthesis of ZnO Nanoneedles by Thermal Oxidation of Zn Thin Films. J. Non. Cryst. Solids 2013, 377, 212-216. https://doi.org/10.1016/j.jnoncrysol.2013.05.003.

(26) Tak, Y.; Yong, K.; Park, C. Selective Growth of ZnO Nanoneedles on Si Substrates by Metalorganic Chemical Vapor Deposition. J. Cryst. Growth 2005, 285 (4), 549-554. https://doi.org/10.1016/j.jcrysgro.2005.09.052.

(27) Liu, Y.; Xu, W.; Shan, Y.; Xu, H. High Reactivity of the ZnO(0001) Polar Surface: The Role of Oxygen Adatoms. J. Phys. Chem. C 2017, 121 (29), 15711-15718. https://doi.org/10.1021/acs.jpcc.7b03326.

(28) Chen, C.; Yu, B.; Liu, J.; Dai, Q.; Zhu, Y. Investigation of ZnO Films on Si<111> Substrate Grown by Low Energy O+ Assisted Pulse Laser Deposited Technology. Mater. Lett. 2007, 61 (14-15), 2961-2964. https://doi.org/10.1016/j.matlet.2006.10.047.

(29) Ko, H. J.; Hong, S. K.; Chen, Y.; Yao, T. A Challenge in Molecular Beam Epitaxy of ZnO: Control of Material Properties by Interface Engineering. Thin Solid Films 2002, 409 (1), 153-160. https://doi.org/10.1016/S0040-6090(02)00119-0.

(30) Feng, L.; Liu, A.; Liu, M.; Ma, Y.; Wei, J.; Man, B. Fabrication and Characterization of Tetrapodlike $\mathrm{ZnO}$ Nanostructures Prepared by Catalyst-Free Thermal Evaporation. Mater. Charact. 2010, 61 (1), 128-133. https://doi.org/10.1016/j.matchar.2009.10.011.

(31) Chien, F. S. S.; Wang, C. R.; Chan, Y. L.; Lin, H. L.; Chen, M. H.; Wu, R. J. Fast-Response Ozone Sensor with ZnO Nanorods Grown by Chemical Vapor Deposition. Sensors Actuators, B Chem. 2010, 144 (1), 120-125. https://doi.org/10.1016/j.snb.2009.10.043.

(32) Joshi, S.; Parmar, M.; Rajanna, K. A Novel Gas Flow Sensing Application Using Piezoelectric ZnO Thin Films Deposited on Phynox Alloy. Sensors Actuators, A Phys. 2012, 187, 194-200. https://doi.org/10.1016/j.sna.2012.08.032.

(33) Sathasivam, S.; Arnepalli, R. R.; Kumar, B.; Singh, K. K.; Visser, R. J.; Blackman, C. S.; Carmalt, C. J. Solution Processing of GaAs Thin Films for Photovoltaic Applications. Chem. Mater. 2014, 26 (15), 4419-4424.

(34) Powell, M. J.; Carmalt, C. J. Aerosols: A Sustainable Route to Functional Materials. Chem. - A Eur. J. 2017. https://doi.org/10.1002/chem.201703347.

(35) Marchand, P.; Hassan, I. A.; Parkin, I. P.; Carmalt, C. J. Aerosol-Assisted Delivery of Precursors for Chemical Vapour Deposition: Expanding the Scope of CVD for Materials Fabrication. Dalton Trans. 2013, 42 (26), 9406-9422. https://doi.org/10.1039/c3dt50607j.

(36) Chadwick, N.; Sathasivam, S.; Kafizas, A.; Bawaked, S. M.; Obaid, A. Y.; Al-Thabaiti, S.; Basahel, S. N.; Parkin, I. P.; Carmalt, C. J. Combinatorial Aerosol Assisted Chemical Vapour 
Deposition of a Photocatalytic Mixed SnO 2/TiO 2 Thin Film. J. Mater. Chem. A 2014, 2 (14), 5108-5116.

(37) Alotaibi, A. M.; Sathasivam, S.; Williamson, B. A. D.; Kafizas, A.; Sotelo-Vazquez, C.; Taylor, A.; Scanlon, D. O.; Parkin, I. P. Chemical Vapor Deposition of Photocatalytically Active Pure Brookite TiO2 Thin Films. Chem. Mater. 2018, 30 (4), 1353-1361.

(38) Hassan, I. A.; Ratnasothy, A.; Bhachu, D. S.; Sathasivam, S.; Carmalt, C. J. The Effect of Solvent on the Morphology of Indium Oxide Deposited by Aerosol-Assisted Chemical Vapour Deposition. Aust. J. Chem. 2013, 66 (10), 1274-1280.

(39) Liqiang, J.; Yichun, Q.; Baiqi, W.; Shudan, L. Review of Photoluminescence Performance of Nano-Sized Semiconductor Materials and Its Relationships with Photocatalytic Activity. 2006, 90, 1773-1787. https://doi.org/10.1016/j.solmat.2005.11.007.

(40) Zheng, Y.; Chen, C.; Zhan, Y.; Lin, X.; Zheng, Q.; Wei, K.; Zhu, J.; Zhu, Y. Luminescence and Photocatalytic Activity of ZnO Nanocrystals: Correlation between Structure and Property. Inorg. Chem. 2007, 46 (16), 6675-6682. https://doi.org/10.1021/ic062394m.

(41) Guo, M. Y.; Ng, A. M. C.; Liu, F.; Djuri??i??, A. B.; Chan, W. K.; Su, H.; Wong, K. S. Effect of Native Defects on Photocatalytic Properties of ZnO. J. Phys. Chem. C 2011, 115 (22), 1109511101. https://doi.org/10.1021/jp200926u.

(42) Mittal, K. L. Adhesion Measurement of Thin Films. Electrocompon. Sci. Technol. 1976, 3 (1), 21-42. https://doi.org/10.1155/APEC.3.21.

(43) Powell, M. J.; Quesada-Cabrera, R.; Travis, W. L.; Parkin, I. P. High-Throughput Synthesis of Core-Shell and Multi-Shelled Materials by Fluidised Bed Chemical Vapour Deposition. Case Study: Double-Shell Rutile-Anatase Particles. J. Mater. Chem. A 2015, 3 (33), 17241-17247. https://doi.org/10.1039/c5ta03526k.

(44) Quesada-Cabrera, R.; Sotelo-Vazquez, C.; Bear, J. C.; Darr, J. A.; Parkin, I. P. Photocatalytic Evidence of the Rutile-to-Anatase Electron Transfer in Titania. Adv. Mater. Interfaces 2014, 1 (6), 1-7. https://doi.org/10.1002/admi.201400069.

(45) Chen, S.; Wilson, R. M.; Binions, R. Synthesis of Highly Surface-Textured ZnO Thin Films by Aerosol Assisted Chemical Vapour Deposition. J. Mater. Chem. A 2015, 3 (11), 5794-5797. https://doi.org/10.1039/C5TA00446B.

(46) Tian, Z. R.; Voigt, J. A.; Liu, J.; Mckenzie, B.; Mcdermott, M. J.; Rodriguez, M. A.; Konishi, H.; $\mathrm{Xu}, \mathrm{H}$. Complex and Oriented ZnO Nanostructures. Nat. Mater. 2003, 2 (12), 821-826. https://doi.org/10.1038/nmat1014.

(47) Zhou, X.; Xie, Z.-X.; Jiang, Z.-Y.; Kuang, Q.; Zhang, S.-H.; Xu, T.; Huang, R.-B.; Zheng, L.-S. Formation of $\mathrm{ZnO}$ Hexagonal Micro-Pyramids: A Successful Control of the Exposed Polar Surfaces with the Assistance of an Ionic Liquid. Chem. Commun. 2005, 1 (44), 5572. https://doi.org/10.1039/b510287a.

(48) Herring, N. P.; Abouzeid, K.; Mohamed, M. B.; Pinsk, J.; El-Shall, M. S. Formation Mechanisms of Gold-Zinc Oxide Hexagonal Nanopyramids by Heterogeneous Nucleation Using Microwave Synthesis. Langmuir 2011, 27 (24), 15146-15154. https://doi.org/10.1021/la201698k.

(49) Nicholas, N. J.; Franks, G. V.; Ducker, W. A. Selective Adsorption to Particular Crystal Faces of ZnO. Langmuir 2012, 28 (18), 7189-7196. https://doi.org/10.1021/la2050674.

(50) Peng, Y.; Ji, J.; Zhao, X.; Wan, H.; Chen, D. Preparation of ZnO Nanopowder by a Novel Ultrasound Assisted Non-Hydrolytic Sol-Gel Process and Its Application in Photocatalytic Degradation of C.I. Acid Red 249. Powder Technol. 2013, 233, 325-330. 
https://doi.org/10.1016/j.powtec.2012.09.018.

(51) Vallejos, S.; Pizúrová, N.; Gràcia, I.; Sotelo-Vazquez, C.; Čechal, J.; Blackman, C.; Parkin, I.; Cané, C. ZnO Rods with Exposed $\{100\}$ Facets Grown via a Self-Catalyzed Vapor-Solid Mechanism and Their Photocatalytic and Gas Sensing Properties. ACS Appl. Mater. Interfaces 2016, 8 (48), 33335-33342. https://doi.org/10.1021/acsami.6b12992.

(52) Li, D.; Huang, J. F.; Cao, L. Y.; Li, J. Y.; Ouyang, H. B.; Yao, C. Y. Microwave Hydrothermal Synthesis of $\mathrm{Sr} 2+$ doped $\mathrm{ZnO}$ Crystallites with Enhanced Photocatalytic Properties. Ceram. Int. 2014, 40 (2), 2647-2653. https://doi.org/10.1016/j.ceramint.2013.10.061.

(53) Shaban, M.; El Sayed, A. M. Effects of Lanthanum and Sodium on the Structural, Optical and Hydrophilic Properties of Sol-Gel Derived ZnO Films: A Comparative Study. Mater. Sci. Semicond. Process. 2016, 41, 323-334. https://doi.org/10.1016/j.mssp.2015.09.002.

(54) Muchuweni, E.; Sathiaraj, T. S.; Nyakotyo, H. Synthesis and Characterization of Zinc Oxide Thin Films for Optoelectronic Applications. Heliyon 2017, 3 (4), e00285. https://doi.org/10.1016/j.heliyon.2017.e00285.

(55) Djurišić, A. B.; Choy, W. C. H.; Roy, V. A. L.; Leung, Y. H.; Kwong, C. Y.; Cheah, K. W.; Rao, T. K. G.; Chan, W. K.; Lui, H. F.; Surya, C. Photoluminescence and Electron Paramagnetic Resonance of ZnO Tetrapod Structures. Adv. Funct. Mater. 2004, 14 (9), 856-864. https://doi.org/10.1002/adfm.200305082.

(56) Kwok, W. M.; Djurišić, A. B.; Leung, Y. H.; Chan, W. K.; Phillips, D. L. Time-Resolved Photoluminescence from ZnO Nanostructures. Appl. Phys. Lett. 2005, 87 (22), 1-3. https://doi.org/10.1063/1.2137456.

(57) Studenikin, S. A.; Golego, N.; Cocivera, M. Fabrication of Green and Orange Photoluminescent, Undoped ZnO Films Using Spray Pyrolysis. J. Appl. Phys. 1998, 84 (4), 2287-2294. https://doi.org/10.1063/1.368295.

(58) Li, D.; Leung, Y. H.; Djurišić, A. B.; Liu, Z. T.; Xie, M. H.; Shi, S. L.; Xu, S. J.; Chan, W. K. Different Origins of Visible Luminescence in ZnO Nanostructures Fabricated by the Chemical and Evaporation Methods. Appl. Phys. Lett. 2004, 85 (9), 1601-1603. https://doi.org/10.1063/1.1786375.

(59) Tam, K. H.; Cheung, C. K.; Leung, Y. H.; Djurišić, A. B.; Ling, C. C.; Beling, C. D.; Fung, S.; Kwok, W. M.; Chan, W. K.; Phillips, D. L.; et al. Defects in ZnO Nanorods Prepared by a Hydrothermal Method. J. Phys. Chem. B 2006, 110 (42), 20865-20871. https://doi.org/10.1021/jp063239w.

(60) Drouilly, C.; Krafft, J. M.; Averseng, F.; Casale, S.; Bazer-Bachi, D.; Chizallet, C.; Lecocq, V.; Vezin, H.; Lauron-Pernot, H.; Costentin, G. ZnO Oxygen Vacancies Formation and Filling Followed by in Situ Photoluminescence and in Situ EPR. J. Phys. Chem. C 2012, 116 (40), 21297-21307. https://doi.org/10.1021/jp307693y.

(61) Yun, H. J.; Lee, H.; Joo, J. B.; Kim, W.; Yi, J. Influence of Aspect Ratio of TiO 2 Nanorods on the Photocatalytic Decomposition of Formic Acid. J. Phys. Chem. C 2009, 113 (8), 3050-3055. https://doi.org/10.1021/jp808604t.

(62) Kong, M.; Li, Y.; Chen, X.; Tian, T.; Fang, P.; Zheng, F.; Zhao, X. Tuning the Relative Concentration Ratio of Bulk Defects to Surface Defects in TiO2nanocrystals Leads to High Photocatalytic Efficiency. J. Am. Chem. Soc. 2011, 133 (41), 16414-16417. https://doi.org/10.1021/ja207826q. 
